\title{
Inteligência de negócios e inteligência competitiva na ciência da informação brasileira: contribuições para uma análise terminológica
}

\begin{abstract}
Alexandre Lucas
\end{abstract}
\begin{abstract}
Doutorando em Ciência da Informação - PGCIN UFSC.Mestrado em Ciência da Informação PGCIN - UFSC.Especialização em Engenharia Industrial - FURB.Engenheiro de Produção Mecânica - UFSC
\end{abstract}

Ligia Maria Arruda Café

Professora do Programa de Pós Graduação em Ciência da Informação - PGCIN Universidade Federal de Santa Catariana - UFSC

Angel Freddy Godoy Viera

Professor do Programa de Pós Graduação em Ciência da Informação - PGCIN Universidade Federal de Santa Catariana - UFSC

http://dx.doi.org/10.1590/1981-5344/2568

O artigo apresenta aspectos da diversidade terminológica relacionada à Inteligência de Negócios e Inteligência Competitiva na produção científica da área da Ciência da Informação brasileira, caracterizando ocorrências de polissemia e sinonímia, e, buscando contribuir para redução da ambiguidade do campo conceitual da área. Foram analisados 29 artigos de 101 encontrados na base BRAPCI. Desses artigos foram extraídos 40 conceitos, os quais foram submetidos à análise, conforme: a) os termos e conceitos de referência, b) as categorias Processo, Função, Produto ou Tecnologia e, c) associação de autores por conceito de referência. Os resultados mostram que: a) se confirma a existência dos fenômenos de polissemia e sinonímia, b) embora o termo Inteligência Competitiva tenha sido predominantemente adotado pelos autores, ele se apresenta com uma ampla variedade de conceitos, c) predominância da categoria processo, d) dispersão de sentidos na análise cronológica, não sobressaindo predominância de um ou outro conceito referencial e, e) categoria tecnologia apresenta-se concentrada nas 
publicações entre 1999 e 2001. Conclui que, tendo em vista a fragilidade terminológica constatada por esta pesquisa, deve-se aprofundar a análise desses termos e conceitos verificando o seu comportamento em áreas afins a aqui estudada, o que certamente mostraria outros aspectos da diversidade terminológica.

Palavras-chave: Inteligência de Negócios; Inteligência Competitiva; Análise terminológica.

\section{Business intelligence and competitive intelligence in brazilian information science: contributions to an analysis terminological}

The article presents aspects of diversity terminology related to Business Intelligence and Competitive Intelligence in the scientific production of the Brazilian Information Science, characterizing occurrences of polysemy and synonymy and seeking to contribute to reducing the ambiguity of the conceptual field. We analyzed 29 articles of 101 found in BRAPCI basis. These articles were extracted from 40 concepts, which were submitted to analysis as a) the terms and concepts of reference, (b) the categories Process, Function, Product or Technology, and c) association of authors by concept of reference. The results show that: (a) confirm the existence of the phenomena of polysemy and synonymy, (b) although the term Competitive Intelligence has been predominantly adopted by the authors, (c) predominance of process category, (d) dispersion of senses in chronological analysis, not protruding predominance of one or the other concept referential and e) technology category is concentrated in publications between 1999 and 2001. It is concluded that, in view of the fragility terminology found in this survey, it should be a more indepth analysis of these terms and concepts by checking its behavior in areas related to the studied here, which certainly would show other aspects of diversity terminology.

Keywords: Business Intelligence; Competitive Intelligence; Terminological Analysis. 


\section{Introdução}

O mundo globalizado no seu aspecto econômico promoveu um amplo ambiente de competição entre empresas, institutos de Ciência, Tecnologia e Inovação (ICTI), governos, países e continentes. Esta competição abrange várias dimensões, entre elas a dimensão da informação. A passagem da era industrial para sociedade da informação trouxe novamente para primeiro plano a informação e o conhecimento. A informação registrada foi alavancada com Gutenberg, no século XV, porém, tomou proporções exponenciais no século $X X$, com a Internet. $O$ uso massivo de sistemas informacionais por toda da sociedade, principalmente no ambiente empresarial, também foi impulsionado pela redução de custos de hardware, software e acesso à Internet, o que pode ser verificado pela infinidade de bancos de dados, de todos os tipos e estrutura, existentes na atualidade. Nesse cenário é possível afirmar que:
a)a informação é considerada chave para alcançar a vantagem competitiva;
b)ela é considerada vital para tomada de decisões e se encontra nas bases de dados corporativas;
c)estas bases são montanhas de dados disseminados por todas as partes;

d)a chave para ganhar vantagem competitiva reside na obtenção de inteligência desses dados: converter dados em conhecimento. (TODESCO et al., 2007)

Estas constatações representam algumas das bases em que a Inteligência de Negócios e a Inteligência Competitiva se ancoram para apoiar tomadas de decisões estratégicas e obtenção de vantagem competitiva, aproveitando todo o potencial da informação.

A Ciência da Informação vem se interessando pelos estudos, especialmente sobre Inteligência Competitiva. Perucchi e Araújo Júnior (2012), em seu artigo sobre a Inteligência Competitiva na Ciência da Informação da Universidade de Brasília (UnB), apresentam elementos importantes para pesquisas neste campo desenvolvidas pela Ciência da Informação brasileira. Entre eles, é importante ressaltar a condição da Inteligência Competitiva como uma ferramenta auxiliar para tomadas de decisão e como uma necessidade moderna das organizações. Os autores ainda mencionam ter a Inteligência Competitiva despertado muitos interesses e estudos, tanto no âmbito das organizações como no das universidades onde existam cursos ou disciplinas na área. No que se refere a sua origem, Pinheiro (2005) esclarece que a Sociedade da Informação e do Conhecimento surge associada à emergência das novas tecnologias de informação e comunicação, na qual o ativo informação assume papel central. Conforme Perucchi e Araújo Júnior (2012), a Inteligência Competitiva é uma área interdisciplinar e sua constituição 
epistemológica e aplicada recorre principalmente a conhecimentos de Administração, Ciência da Informação, Ciência da Computação e Economia, sendo ela uma disciplina relativamente nova, tanto no exterior quanto no Brasil, onde é mais recente ainda. $O$ fato de se tratar de uma disciplina jovem pode ser uma das causas pelas quais seus significados estejam ainda em formação. Desta forma, entende-se que seja natural que seus conceitos estejam, também, em processo de elaboração e ainda não consolidados (PERUCCHI; ARAÚJO JÚNIOR, 2012). Do ponto de vista da publicação científica, Amaral (2010, p. 84) registra que as iniciativas brasileiras na produção de monografias, dissertações e teses sobre Inteligência Competitiva estão concentradas nas áreas de Administração, Ciência da Informação e Engenharia da Produção, áreas do conhecimento responsáveis por $82 \%$ das publicações. Na busca de sintetizar o conceito de Inteligência Competitiva e aproximá-lo da Ciência da Informação, Perucchi e Araújo Júnior (2012) apresentam a Inteligência Competitiva como atividade exercida com o objetivo de produzir informação de interesse de determinada organização, e desta forma Inteligência Competitiva e Ciência da Informação estão direcionadas para o mesmo objeto, isto é, a informação. Quanto ao período em que esta temática apresenta seus primeiros registros, Pinheiro (2005) relata que, embora alguns autores apontem que as primeiras manifestações de Inteligência Competitiva ocorreram nas décadas de 1960 e 1970, e outros relatem que datam dos anos 1980, nos Estados Unidos, na Ciência da informação, ela surge como disciplina na década de 80.

No que se refere à Inteligência de Negócios, existem bem menos iniciativas de pesquisa no campo da Ciência da Informação nesta área. Observa-se, no entanto que, na literatura tanto em inglês como em português, os termos Inteligência de Negócios e Inteligência Competitiva (e seus respectivos termos na língua inglesa) são usados de forma indiscriminada, provocando variações tanto denominativa como conceitual. Esta diversidade terminológica pode inclusive estar influenciando a determinação quanto à dimensão da produtividade de pesquisas nestes campos do conhecimento.

Diante do exposto, o presente artigo visa investigar esta questão terminológica, apoiando-se em aspectos apresentados no referencial teórico e análises dos conceitos utilizados em artigos científicos da Ciência da Informação, buscando assim contribuir com a redução da ambiguidade conceitual dos termos nestes campos. Cabe ainda destacar que este trabalho foi concebido como parte da dissertação intitulada "Inteligência de Negócios em Instituições de Ciência, Tecnologia e Inovação (ICTIs): análise da produção científica", do Programa de PósGraduação da Ciência da Informação (PGCIN), da Universidade Federal de Santa Catarina (UFSC).

\section{Diversidade terminológica}

$\mathrm{Na}$ literatura científica em inglês, segundo Bergeron e Hiller (2002), não há um acordo terminológico no uso dos termos competitive intelligence, business intelligence, competitor intelligence e environmental scanning. Acrescenta-se ainda que o conceito de competitive intelligence é multifacetado e difuso, podendo o seu significado ser categorizado como um processo, uma função, um produto, ou uma combinação dos três (GILAD; GILAD, 1988 apud BERGERON; HILLER, 2002).

Esta variação na terminologia também é verificada na literatura em português. O termo Inteligência Empresarial, por exemplo, pode parecer à primeira vista 
simplesmente a tradução para o português do termo em inglês business intelligente (BI), mas esta conclusão nem sempre é verdadeira, conforme entendem Matheus e Parreiras (2004). Na Ciência da Informação constata-se o mesmo fenômeno, mas a ocorrência dos termos nos artigos científicos é relativamente baixa. Uma consulta, em 4 de outubro de 2014, na Base de Dados Referenciais de Artigos de Periódicos em Ciência da Informação (BRAPCI), mostrou um volume total de 7.299 artigos na base e uma busca com os termos Inteligência de Negócios, Inteligência Empresarial, Business Intelligence, Inteligência Competitiva, Competitive Intelligence, em todos os campos da base mostrou que deste total somente $1,3 \%$ continha pelo menos um dos termos.

A seguir aponta-se as principais características do conceito dos termos Inteligência de Negócios e Inteligência Competitiva, objetos de nosso estudo.

\subsection{Inteligência de negócios}

Nesta seção apresenta-se a base de construção do primeiro conceito referencial, Inteligência de Negócios, adotado como objeto de estudo desta pesquisa.

Em 2007, ocorreu em Florianópolis, na Universidade Federal de Santa Catarina (UFSC), uma edição da Escuela Complutense Latinoamericana. Dentre os diversos cursos com duração de duas semanas, aconteceu o de Inteligência de Negócios, termo traduzido do inglês Business Intelligence. Neste evento, Todesco et al. (2007) apresentaram o conceito da seguinte forma: "Inteligência de Negócios ou Business Intelligence é um termo contemporâneo usado para se referir a um conjunto de tecnologias de informação (plataformas, aplicações e processos), que visa facilitar a tomada de decisões em todos os níveis".

Observa-se que os autores consideram os termos Inteligência de Negócios e Business Intelligence como equivalentes, isto é, referem-se ao mesmo significado. Como complemento ao conceito, foi acrescentado que Inteligência de Negócios ou Business Intelligence tem igualmente o sentido de conjunto de ferramentas e aplicativos que ajudam na tomada de decisões, que permitem o acesso interativo, análise e manipulação de informações corporativas de missão crítica. Os autores também completam o significado listando os seguintes atributos:

a)o sistema de armazenamento dos dados, DataWarehouse (armazém geral de dados) e os Data Marts (banco de dados de sistemas específicos) estrutura normalmente baseadas na visão de Ralph Kimball;

b)sistemas de suporte a decisão ou Sistema de Apoio a Decisão (SAD) incluindo um conjunto sistemas conhecidos por suas siglas Management Information System (MIS), Decision Support System (DSS), Executive Support System (ESS), Expert systems based on artificial intelligence (SSEE) e Group Decision Support Systems (GDSS); 
c)sistemas de mineração de dados (data minning) e de análise Multidimensional (OLAP);

d)sistemas de gestão Empresarial (ERP) e de relacionamentos com clientes (CRM). (TODESCO; CARRETERO; DURAN, 2007).

\subsection{Inteligência competitiva}

O segundo conceito referencial, Inteligência Competitiva, baseia-se na definição de Competitive Intelligence, registrada por Bergeron e Hiller (2002), em um artigo de revisão publicado na Annual Review of Information Science and Technology (ARIST). Segundo os autores, Inteligência Competitiva é:

um processo de aprendizagem micro organizacional que envolve a transformação de pedaços aparentemente díspares de dados e informações, por meio de sentido, de geração de conhecimento e de atividades de tomada de decisão, em uma única forma organizada, em constante evolução com a visão do mundo (BERGERON; HILLER, 2002, p. 359).

Trata-se de um conceito mais amplo e menos enfático no que se refere ao aspecto computacional. Os autores tomam por base a obra de Choo (2003), já traduzida para o português, na época 1998, denominada "A organização do conhecimento: como as organizações usam a informação para criar significado, construir conhecimento e tomar decisões".

Considera-se também importante o significado registrado por Gibbons e Prescott (1996, p. 164, tradução nossa) em registram que Inteligência Competitiva é "o processo de obtenção, análise, interpretação e difusão de informação de valor estratégico sobre a indústria e os competidores, que se transmite aos responsáveis pela tomada de decisões em momento oportuno".

Uma primeira análise mostra que o sentido de Inteligência de Negócios trata de "um conjunto de tecnologias" enquanto o conceito de Inteligência Competitiva aponta para "um processo de aprendizagem". Porém o atributo "dados e informação para tomada de decisão" permeiam ambos os conceitos.

\subsection{Polissemia e sinonímia}

A principal função da linguagem é a comunicação, papel exercido por um sistema de signos verbais ou gráficos. Considerada como um subsistema da linguagem geral, a linguagem especializada se compõe de lexemas adotados para a comunicação em áreas de conhecimento especializados. As comunidades científicas e tecnológicas adotam estas 
linguagens, enriquecendo-as com novos termos e conceitos conforme o desenvolvimento da área.

Nos domínios especializados, os países detentores do conhecimento científico e tecnológico de ponta criam neologismos para cada objeto descoberto. Estes neologismos são transferidos para os países importadores desta "nova ciência e tecnologia" que absorvem a terminologia adaptando-a ao contexto nacional. Este processo tem como consequência o surgimento de ambiguidades que podem afetar a comunicação entre especialistas. Estas ambiguidades podem ter naturezas diversas provenientes das relações entre denominação (forma/significante) e conceito (significado). Segundo Cabré (1993), em teoria, nas terminologias das áreas de especialidade, os termos são unívocos (unicidade na relação entre forma e conceito) e monorreferenciais (um termo só designa um objeto). Porém, segundo a autora, na realidade, além da relação entre forma e conceito não serem unívocas, elas são múltiplas. Uma forma pode ter vários significados, o que se denomina polissemia, assim como um conceito pode ser denominado por várias formas, o que se nomeia como sinonímia.

Para análise do objeto de estudo desta pesquisa, tomou-se como base os princípios que fundamentam o domínio da Socioterminologia, campo de estudos que tem como objetivo analisar os termos em circulação tanto na perspectiva diacrônica como sincrônica, mostrando as variações presentes nos níveis da significação e da terminologia adotada em uma área do conhecimento. Nessa perspectiva, é possível tecer considerações mais aprofundadas sobre os fenômenos linguísticos denominados como sinonímia e polissemia. Segundo Gaudin (2005, p. 81), a Socioterminologia...

[..] possède une dimension sociocritique, comme toute sémantique du discours, dans la mesure où elle relie la production de sens des termes avec les conditions de leur apparition. La circulation des termes est envisagée sous l'angle de la diversité de leurs usages sociaux, ce qui englobe à la fois l'étude des conditions de circulation et d'appropriation des termes, envisagés comme des signes linguistiques, et non comme des étiquettes de concepts.

No caso do presente estudo, as condições de circulação e apropriação dos termos foram verificadas no uso dos termos Inteligência de Negócios e Inteligência Competitiva na produção científica em português do Brasil, publicada na Ciência da Informação.

\section{Procedimento metodológico}

Considerando os conceitos referenciais escolhidos para Inteligência de Negócios e Inteligência Competitiva e os fenômenos de polissemia e 
sinonímia descritos, apresenta-se, nesta seção, os passos para verificar o uso destes termos e seus respectivos conceitos nos artigos publicados em Ciência da Informação.

Esta pesquisa bibliográfica se caracteriza como qualitativa no que se refere à abordagem do problema. Seu caráter exploratório e descritivo é verificado pela análise terminológica guiada pelos conceitos referenciais norteadores.

A primeira etapa consistiu em identificar os artigos na base de dados da BRAPCI para cada um dos termos escolhidos para a pesquisa. Para tanto, a expressão de busca foi realizada no campo "todos", selecionando os termos em português: Inteligência de Negócios e Inteligência Competitiva. Na busca também foram inclusos os termos Inteligência Empresarial e Monitoramento do Ambiente, pois aparecem como sinônimos nos artigos de Bergeron e Hiller (2002) e de Matheus e Parreiras (2004). A busca utilizou o operador 'OR' e com todos os termos simultaneamente. O uso do campo "todos" resultou em um grande número de artigos relevantes recuperados, favorecendo, assim, a revocação. No entanto, a precisão foi afetada, recuperando-se muito "lixo", ou seja, artigos repetidos ou artigos que somente apresentavam o termo no campo "palavra-chave", sem mencioná-lo em qualquer outra parte do texto.

Foram recuperados 101 artigos, os quais foram selecionados obedecendo ao seguinte critério: até 10 artigos por termo e, no caso de resultados com mais de dez artigos, foram analisados somente os dez mais recentes, o que resultou em um total de 29 artigos selecionados para a pesquisa. A Tabela 1 mostra o resultado por termo de busca:

Tabela 1 - Artigos recuperados segundo o termo de busca utilizado

\begin{tabular}{l|c|c}
\hline \multicolumn{1}{c|}{ Termos } & $\begin{array}{c}\text { Artigos encontrados } \\
\text { BRAPCI }\end{array}$ & $\begin{array}{c}\text { Artigos analisados } \\
\text { BRAPCl }\end{array}$ \\
\hline \hline Inteligência de Negócios & 2 & 2 \\
\hline Inteligência Competitiva & 82 & 10 \\
\hline Inteligência Empresarial & 10 & 10 \\
\hline Monitoramento do Ambiente & 7 & 7 \\
\hline Total & 101 & 29 \\
\hline
\end{tabular}

Fonte: Dados da pesquisa (2015).

A segunda etapa consistiu em analisar os conceitos presentes para todos os termos escolhidos e não só o utilizado para a busca. Ou seja, o artigo recuperado pelo termo Inteligência de Negócios também foi analisado com relação aos conceitos de apresentados para Inteligência Competitiva, Inteligência Empresarial e Monitoramento do Ambiente, caso ocorressem. Alguns artigos encontrados, por exemplo, faziam revisão da literatura e apresentaram vários conceitos.

Esta análise foi realizada em três perspectivas. A primeira buscou classificar os termos conforme sua semelhança em relação aos conceitos 
de referência para Inteligência de Negócios e Inteligência Competitiva, observando os fenômenos de sinonímia e polissemia.

Na segunda perspectiva, baseando-se na afirmação de Gilad e Gilad (1988 apud BERGERON; HILLER, 2002) de que Inteligência Competitiva é genericamente apresentada como um processo, uma função, um produto, ou uma combinação de todos os três, buscou-se categorizar os conceitos recuperados quanto a estas "apropriações", acrescentando-se uma quarta categoria aqui denominada tecnologia, contemplada no conceito de referência para Inteligência de Negócios.

Para auxiliar nesta classificação, foram utilizados os conceitos de processo, função, produto e tecnologia estabelecidos pelo Dicionário de Biblioteconomia e Arquivologia Cunha; Cavalcanti (2008):

a)processo: Conjunto de recursos e atividades interrelacionadas que transformam insumos (entradas) em produtos (saídas);

b)função: Etapa de processamento das operações;

c)produto: Resulta das atividades ou processo;

d)tecnologia: Recurso físico útil, que serve como instrumento ou meio de realizar alguma coisa. Qualquer técnica poderá fazer uso maior ou menor de diferentes tecnologias.

Para uma coerência com os referenciais conceituais, os conceitos classificados coincidentes com o de Inteligência de Negócios tiveram uma classificação de apropriação como 'Tecnologia' por se tratar como um conjunto de tecnologias e quando coincidente com o de Inteligência Competitiva foram classificados como 'processo'.

A terceira perspectiva tratou de associar os conceitos com os autores, agrupando-os conforme as categorias, a fim de identificar correntes de pensamento.

Associada a esta terceira perspectiva, verificou-se cronologicamente a adoção da terminologia pelos autores, com o intuito de apresentar um panorama histórico e a predominância de uso dos conceitos analisados neste estudo ao longo do tempo.

\section{Análise dos resultados}

Com a intenção de apresentar um panorama geral inicial dos resultados encontrados, apresenta-se, nas Tabelas 2 a 5, os 40 conceitos identificados, classificados em ordem decrescente do ano de publicação, podendo ser igual ou diferente ao do conceito norteador utilizado por este estudo. 
Tabela 2 - Conceitos encontrados para Inteligência de Negócios

\begin{tabular}{l|c|c}
\hline \multicolumn{1}{c|}{ Conceito } & Autor & Ano \\
\hline \hline $\begin{array}{l}\text { É um processo que envolve a coleta, análise e validação de } \\
\text { informações sobre concorrentes, clientes, fornecedores, } \\
\begin{array}{l}\text { candidatos potenciais à aquisição, candidatos a joint- } \\
\text { ventures e alianças estratégicas. }\end{array}\end{array}$ & TYSON, K. W. M. & 1997 \\
\hline
\end{tabular}

Fonte: Dados da pesquisa (2014).

Tabela 3 - Conceitos encontrados para Inteligência Competitiva

\begin{tabular}{|c|c|c|}
\hline Conceito & Autor & Ano \\
\hline $\begin{array}{l}\text { É um Sistema de Gestão Estratégica de Informação, que } \\
\text { tem como objetivo permitir que os tomadores de decisão se } \\
\text { antecipem sobre as tendências dos mercados e a evolução } \\
\text { da concorrência; detectem e avaliem ameaças e } \\
\text { oportunidades que se apresentam no seu ambiente, para } \\
\text { definirem as ações ofensivas e defensivas mais adaptadas } \\
\text { às estratégias de desenvolvimento da organização. }\end{array}$ & JAKOBIAK, F. & 1991 \\
\hline $\begin{array}{l}\text { É a informação analisada para tomada de decisão e o } \\
\text { processo analítico que transforma informação desagregada } \\
\text { em conhecimento relevante, acurado e útil sobre a posição, } \\
\text { performance, capacidades e intenções dos competidores. }\end{array}$ & FULD, L. M. & 1994 \\
\hline $\begin{array}{l}\text { É um processo sistemático voltado para a produção de } \\
\text { informação sob medida, para auxiliar no planejamento e } \\
\text { nas decisões. }\end{array}$ & FULD, L. M. & 1995 \\
\hline $\begin{array}{l}\text { Envolve um processo contínuo, ético e legal de coleta, } \\
\text { análise e disseminação de informações acionáveis para os } \\
\text { tomadores de decisão, com o propósito de prevenir } \\
\text { ameaças e situações indesejáveis à organização, bem } \\
\text { como fomentar e aproveitar oportunidades para ela. }\end{array}$ & FULD, L. M. & 1995 \\
\hline $\begin{array}{l}\text { Um programa sistemático para coletar e analisar } \\
\text { informação sobre as atividades de seus competidores e } \\
\text { tendências de negócios para atingir os objetivos da } \\
\text { empresa. }\end{array}$ & KAHANER, L. & 1997 \\
\hline $\begin{array}{l}\text { É o conhecimento e previsão dos ambientes externo e } \\
\text { interno da organização, aplicado ao processo de tomada de } \\
\text { decisão, orientando as ações gerenciais, objetivando o } \\
\text { posicionamento e vantagem competitiva. }\end{array}$ & HERRING, J. P. & 1997 \\
\hline $\begin{array}{l}\text { Explicita a informação analisada para tomada de decisão, } \\
\text { visando à obtenção de uma vantagem competitiva. }\end{array}$ & KAHANER, L. & 1997 \\
\hline $\begin{array}{l}\text { É a informação externa e as estratégias de inteligência [que } \\
\text { possibilitam] inovação. }\end{array}$ & $\begin{array}{l}\text { POZZEBON, M.; } \\
\text { FREITAS, H. M. } \\
\text { R.; PETRINI, M. }\end{array}$ & 1997 \\
\hline $\begin{array}{l}\text { É um processo analítico do começo ao fim, que associa } \\
\text { partes de informações, sobre os competidores, clientes, } \\
\text { fornecedores, potenciais candidatos à aquisição, potenciais } \\
\text { candidatos a fusões ou alianças estratégicas e virtualmente } \\
\text { informações de todas as entidades e eventos do ambiente } \\
\text { externo da companhia, transformando-as em conhecimento } \\
\text { estratégico. }\end{array}$ & TYSON, K. & 1997 \\
\hline
\end{tabular}




\begin{tabular}{|c|c|c|}
\hline $\begin{array}{l}\text { É a coleta e análise de informações, legal e ética, relativas } \\
\text { às capacidades, vulnerabilidades e intenções dos } \\
\text { concorrentes. }\end{array}$ & $\begin{array}{l}\text { SCIP - Strategic } \\
\text { and Competitive } \\
\text { Intelligence } \\
\text { Professionals }\end{array}$ & 1999 \\
\hline $\begin{array}{l}\text { É um programa de busca e análise da informação sobre os } \\
\text { fatores chaves que influenciam na competitividade da } \\
\text { indústria em geral e da empresa em particular. }\end{array}$ & CALOF, J. L. & 1999 \\
\hline $\begin{array}{l}\text { É o conjunto de processos e ferramentas para selecionar, } \\
\text { analisar, comunicar e gerenciar as informações externas à } \\
\text { empresa. Ou seja, informações sobre seus clientes, } \\
\text { concorrentes, enfim, seu ambiente competitivo. }\end{array}$ & $\begin{array}{l}\text { TEIXEIRA } \\
\text { FILHO, J. }\end{array}$ & 2000 \\
\hline $\begin{array}{l}\text { É uma atividade de monitoramento do ambiente externo à } \\
\text { empresa para obter a informação relevante à tomada de } \\
\text { decisão. }\end{array}$ & GILAD, B. & 2000 \\
\hline $\begin{array}{l}\text { É um conjunto de processos que transforma dados } \\
\text { internos, de alta relevância, associados a dados externos } \\
\text { de mercado em conhecimento, gerando uma base rentável } \\
\text { de clientes que se mantém atraída pela empresa e seus } \\
\text { produtos por identificar e perceber valor no que lhe é } \\
\text { entregue. }\end{array}$ & $\begin{array}{l}\text { MIQUELINO, F. } \\
\text { L. C.; SANTOS, } \\
\text { R.N.M. }\end{array}$ & 2001 \\
\hline $\begin{array}{l}\text { Uma metodologia que permite o monitoramento } \\
\text { informacional do ambiente externo da organização e deve } \\
\text { tornar-se uma prática integrante do processo de gestão } \\
\text { estratégica das organizações, uma vez que ela previne } \\
\text { eventos não previstos que possam afetar o desempenho e } \\
\text { o sucesso organizacional. }\end{array}$ & $\begin{array}{c}\text { TARAPANOFF, } \\
\mathrm{K} .\end{array}$ & 2001 \\
\hline $\begin{array}{l}\hat{E} \text { um processo sistemático que transforma pedaços } \\
\text { esparsos de dados em conhecimento estratégico. É a } \\
\text { informação sobre produtos específicos e Monitoramento da } \\
\text { informação e inteligência competitiva: realidade } \\
\text { organizacional e tecnologia. }\end{array}$ & $\begin{array}{c}\text { TARAPANOFF, } \\
\mathrm{K} .\end{array}$ & 2001 \\
\hline $\begin{array}{l}\text { É um processo de aprendizado motivado pela competição, } \\
\text { fundado sobre a informação, permitindo esta última a } \\
\text { otimização da estratégia corporativa em curto em longo } \\
\text { prazo. Análise dos concorrentes e a tendência geral do } \\
\text { mercado estão entre os principais focos. }\end{array}$ & $\begin{array}{c}\text { TARAPANOFF, } \\
\mathrm{K} .\end{array}$ & 2001 \\
\hline $\begin{array}{l}\text { São técnicas, métodos e ferramentas tecnológicas que } \\
\text { permitem aos usuários analisar dados e, baseado nestas } \\
\text { análises obter respostas que, em avanço, poderão apoiar } \\
\text { decisões confiáveis e objetivas, além de outros processos } \\
\text { gerenciais numa organização. }\end{array}$ & $\begin{array}{l}\text { COMBSINC. } \\
\text { Richard Combs } \\
\text { Associates. }\end{array}$ & 2001 \\
\hline $\begin{array}{l}\text { Um processo informacional proativo, que conduz à melhor } \\
\text { tomada de decisão, seja ela estratégica ou operacional. [...] } \\
\text { Visa descobrir as forças que regem os negócios, reduzir o } \\
\text { risco e conduzir o tomador de decisão a agir } \\
\text { antecipadamente, bem como proteger o conhecimento } \\
\text { gerado. }\end{array}$ & $\begin{array}{l}\text { ABRAIC - } \\
\text { Associação } \\
\text { Brasileira de } \\
\text { Analistas de } \\
\text { Inteligência } \\
\text { Competitiva } \\
\end{array}$ & 2002 \\
\hline $\begin{array}{l}\text { É um processo sistemático e ético para coleta, análise e } \\
\text { gerenciamento das informações externas, que podem } \\
\text { auxiliar nas decisões e nas operações de uma empresa. }\end{array}$ & $\begin{array}{l}\text { SCIP - Strategic } \\
\text { and Competitive } \\
\text { Intelligence } \\
\text { Professionals }\end{array}$ & 2002 \\
\hline
\end{tabular}




\begin{tabular}{|c|c|c|}
\hline $\begin{array}{l}\text { Uso sistematizado de informações obtidas ética e } \\
\text { legalmente, relativas ao ambiente competitivo geral para } \\
\text { que a organização possa estabelecer tendências e cenários } \\
\text { e possam responder mais rapidamente as alterações de } \\
\text { mercado do que seus concorrentes. }\end{array}$ & $\begin{array}{l}\text { PRESCOTT, J. } \\
\text { E.; MILLER, S. H. }\end{array}$ & 2002 \\
\hline $\begin{array}{l}\text { É o processo que se inicia de uma necessidade que a } \\
\text { organização detecta ao se deparar com problemas } \\
\text { complexos e relacionados principalmente à falta de } \\
\text { informação, relativa tanto ao ambiente interno como o } \\
\text { externo. }\end{array}$ & MILLER, J. P. & 2002 \\
\hline $\begin{array}{l}\text { É o desenvolvimento da capacidade criativa do capital } \\
\text { intelectual, focada nas estratégias da organização, com } \\
\text { prospecção, seleção e filtragem de informações } \\
\text { estratégicas nos fluxos informacionais formais e informais. } \\
\text { Agrega, também, valor a tais informações, para serem } \\
\text { utilizadas pelo sistema de informação estratégico, criando e } \\
\text { disponibilizando produtos e serviços voltados à tomada de } \\
\text { decisão. }\end{array}$ & $\begin{array}{l}\text { VALENTIM, M. L. } \\
\text { P. et al. }\end{array}$ & 2002 \\
\hline $\begin{array}{l}\text { A partir de processos sistemáticos de coleta, tratamento, } \\
\text { análise e disseminação da informação sobre o ambiente } \\
\text { competitivo, o concorrencial e o organizacional, visa } \\
\text { subsidiar o processo decisório e atingir as metas } \\
\text { estratégicas da organização. }\end{array}$ & $\begin{array}{l}\text { COELHO, G. M. } \\
\text { et al. }\end{array}$ & 2002 \\
\hline $\begin{array}{l}\text { O processo de investigação do ambiente externo à } \\
\text { organização, bem como de diagnóstico do ambiente interno } \\
\text { organizacional, com o propósito de descobrir oportunidades } \\
\text { e reduzir os riscos, visando o estabelecimento de } \\
\text { estratégias de ação a curto, médio e longo prazo. }\end{array}$ & $\begin{array}{l}\text { VALENTIM, M. L. } \\
\text { P. et al. }\end{array}$ & 2003 \\
\hline $\begin{array}{l}\text { Um programa sistemático e ético de coleta, análise, } \\
\text { disseminação e gerenciamento das informações sobre o } \\
\text { ambiente externo, que podem afetar os planos, as decisões } \\
\text { e a operação da organização. }\end{array}$ & $\begin{array}{l}\text { SCIP - Strategic } \\
\text { and Competitive } \\
\text { Intelligence } \\
\text { Professionals }\end{array}$ & 2004 \\
\hline $\begin{array}{l}\text { É a atividade de inteligência cujo objetivo é a manutenção } \\
\text { ou o aumento da competitividade das organizações. Seu } \\
\text { ciclo de produção engloba as fases de planejamento, } \\
\text { coleta, análise e disseminação da informação. }\end{array}$ & MARCIAL, E. & 2005 \\
\hline $\begin{array}{l}\text { Um processo de aprendizagem motivado pela competição, } \\
\text { fundada sobre a Informação que permite a otimização da } \\
\text { estratégia da organização de curto e longo prazo. }\end{array}$ & $\begin{array}{l}\text { QUEYRAS, J.; } \\
\text { QUONIAM, L. }\end{array}$ & 2006 \\
\hline $\begin{array}{l}\text { É um sistema de monitoramento de ambiente, no qual } \\
\text { integra o conhecimento de todos na organização. }\end{array}$ & $\begin{array}{l}\text { CALOF, J. L.; } \\
\text { WRIGHT, S. }\end{array}$ & 2008 \\
\hline $\begin{array}{l}\text { É o resultado da análise de Informações e } \\
\text { dados coletados, que irá embasar decisões. }\end{array}$ & SANTOS, R. R. & 2008 \\
\hline $\begin{array}{l}\text { Um processo de monitoramento e análise do ambiente } \\
\text { competitivo em que a organização está inserida, para o } \\
\text { suporte à decisão. }\end{array}$ & $\begin{array}{l}\text { SCIP - Strategic } \\
\text { and Competitive } \\
\text { Intelligence } \\
\text { Professionals }\end{array}$ & 2010 \\
\hline $\begin{array}{l}\text { Um processo de aprendizado, motivado pela competição, e } \\
\text { baseada na informação que fortalece as estratégias da } \\
\text { organização de curto, médio e longo prazo. }\end{array}$ & $\begin{array}{l}\text { HOFFMANN, W. } \\
\text { A. M. }\end{array}$ & 2011 \\
\hline
\end{tabular}




\begin{tabular}{|c|c|c|}
\hline $\begin{array}{l}\text { Inteligência Competitiva consiste em uma atividade de } \\
\text { gestão estratégica da informação dentro de uma } \\
\text { Organização. }\end{array}$ & $\begin{array}{l}\text { SOUSA, B. A.; } \\
\text { SANTOS, E. T. } \\
\text { G. }\end{array}$ & 2012 \\
\hline $\begin{array}{l}\text { É atividade exercida com o objetivo de produzir informação } \\
\text { de interesse de determinada organização. }\end{array}$ & $\begin{array}{l}\text { PERUCCHI, V.; } \\
\text { ARAUJO } \\
\text { JÚNIOR, R. H. }\end{array}$ & 2012 \\
\hline $\begin{array}{l}\text { É a análise das informações sobre o mercado e da geração } \\
\text { de recomendações para os decisores dentro das empresas. } \\
\text { A informação é analisada, de forma minuciosa e com visão } \\
\text { para o mercado em que a companhia está inserida, para } \\
\text { que possa minimizar riscos durante o processo decisório. }\end{array}$ & $\begin{array}{l}\text { TEXEIRA, R. C.; } \\
\text { SOUZA, R. R }\end{array}$ & 2013 \\
\hline
\end{tabular}

Fonte: Dados da pesquisa (2014).

Tabela 4 - Conceitos encontrados para Inteligência Empresarial

\begin{tabular}{|c|c|c|}
\hline Conceito & Autor & Ano \\
\hline $\begin{array}{l}\text { É apoiar o processo de tomada de decisão no nível de uma } \\
\text { empresa e mesmo no nível de planejamento de um país. }\end{array}$ & LAGERSTAM, C. & 1990 \\
\hline $\begin{array}{l}\text { Designa o conjunto de recursos próprios ou mobilizados por } \\
\text { uma entidade lucrativa, destinada a assegurar o acesso, } \\
\text { capturar, interpretar e desenvolver conhecimentos e } \\
\text { informações com alto valor agregado para apoiar a tomada } \\
\text { de decisão requerida pelo desenho e implementação de } \\
\text { sua estratégia competitiva. }\end{array}$ & CUBILLO, J. & 1997 \\
\hline $\begin{array}{l}\text { É o conjunto de atividades voltadas para a obtenção, para o } \\
\text { processamento, a análise e a disseminação de informação } \\
\text { acerca do ambiente de negócios de organizações de } \\
\text { produção, com o objetivo de dar suporte à tomada de } \\
\text { decisão e à definição estratégica. }\end{array}$ & $\begin{array}{l}\text { BORGES, M. E. } \\
\text { N. }\end{array}$ & 2002 \\
\hline
\end{tabular}

Fonte: Dados da pesquisa (2014).

Tabela 5 - Conceitos encontrados para Monitoração do Ambiente

\begin{tabular}{|c|c|c|}
\hline Conceito & Autor & Ano \\
\hline $\begin{array}{l}\text { É a busca de informações sobre eventos e relacionamentos } \\
\text { no ambiente externo de uma empresa, o conhecimento dos } \\
\text { quais irá auxiliar os executivos principais na tarefa de definir } \\
\text { a futura linha de ação da empresa. }\end{array}$ & AGUILAR, F. J. & 1967 \\
\hline
\end{tabular}

Fonte: Dados da pesquisa (2014).

Como pode ser observado nas Tabelas 2 a 5, foram identificados: um conceito denominado por Inteligência de Negócio, 35 conceitos representados por Inteligência Competitiva, três conceitos denominados como Inteligência Empresarial e um conceito denominado de Monitoração do Ambiente. A seguir apresenta-se as três perspectivas de análise dos conceitos identificados. Deste resultado, pode-se concluir que o termo mais utilizado é Inteligência Competitiva, embora, como se verifica na próxima seção, seja adotado com uma ampla variedade de significados. 


\subsection{Classificação conforme os termos e conceitos de referência}

Nesta seção, cada conceito foi comparado com os conceitos de referência e classificado segundo sua coincidência ou semelhança ou ainda nenhuma destas. O resultado é sistematizado na Tabela 6.

Tabela 6 - Termos e conceitos recuperados em relação aos termos e conceitos referenciais

\begin{tabular}{l|c|c|c|c}
\hline $\begin{array}{l}\text { Termo utilizado pelo } \\
\text { autor para o conceito } \\
\text { recuperado }\end{array}$ & $\begin{array}{l}\text { Conceito de } \\
\text { referência } \\
\text { para } \\
\text { inteligência } \\
\text { competitiva }\end{array}$ & $\begin{array}{l}\text { Conceito de } \\
\text { referência para } \\
\text { inteligência de } \\
\text { negócios }\end{array}$ & $\begin{array}{l}\text { Conceito do } \\
\text { autor não } \\
\text { coincide com } \\
\text { os conceitos } \\
\text { de referência }\end{array}$ & $\begin{array}{l}\text { Total dos } \\
\text { conceitos } \\
\text { recuperados }\end{array}$ \\
\hline \hline Inteligência de Negócios & - & 1 & - & 1 \\
\hline Inteligência Competitiva & 17 & 1 & 17 & 35 \\
\hline Inteligência Empresarial & 1 & 1 & 1 & 3 \\
\hline Monitoração do Ambiente & - & - & 1 & 1 \\
\hline Total geral & $\mathbf{1 8}$ & $\mathbf{3}$ & $\mathbf{1 9}$ & $\mathbf{4 0}$ \\
\hline
\end{tabular}

Fonte: Dados da pesquisa (2014).

A Tabela 6 mostra que o termo mais utilizado no corpus foi Inteligência Competitiva. Conforme já verificado anteriormente ele ocorre 35 vezes. Porém, destas somente em 17, este termo e seu conceito correspondente coincidem com o termo e conceito referenciais. Nas demais 18 ocorrências, seus significados diferem ora se aproximando do conceito referencial de Inteligência de Negócios, ora não coincidente em ambos os conceitos referenciais. Ao coincidir com o termo e conceito de referência para Inteligência de Negócios, constata-se a presença de sinonímia, isto é, existem duas formas (Inteligência Competitiva e Inteligência de Negócios) para um mesmo conceito. Ao não coincidir com ambos os conceitos referenciais em 17 ocorrências, comprova-se a existência do fenômeno da polissemia, isto é, uma forma designando mais de um conceito.

Outra observação verificada na Tabela 6 refere-se ao termo e conceito de Inteligência de Negócios, identificados no corpus analisado, que coincidem com o termo e conceito de referência, apresentando-se de forma unívoca e monorreferencial, uma situação ideal para a comunicação entre especialistas.

A sinonímia é constatada, também, quando o termo recuperado Inteligência Empresarial apresenta-se com o mesmo significado para o conceito referencial de Inteligência Competitiva. O mesmo ocorre quando coincide com o sentido referencial de Inteligência de Negócios.

Sob outra perspectiva, pode-se concluir igualmente que o termo Inteligência Empresarial, ao possuir três ocorrências de conceitos diferentes, se enquadraria em uma situação de polissemia. Questão 
também averiguada por Matheus e Parreiras (2004), quando relatam que não existem somente casos de sinonímia para este termo.

Finalmente, quanto ao termo Monitoramento de Ambiente, este apresentou somente um conceito e não foi observada coincidência com os termos e conceitos norteadores desta pesquisa. Portanto, neste caso não foi verificada a presença de sinonímia e polissemia.

\subsection{Classificação conceitual por função, processo, produto e tecnologia}

Nesta etapa, cada conceito foi analisado e classificado conforme as categorias função, processo, produto e tecnologia, cujo resultado apresenta-se na Tabela 7.

Tabela 7- Classificação conceitual por função, processo, produto e tecnologia

\begin{tabular}{|c|c|c|c|c|c|}
\hline \multirow{2}{*}{ Termo utilizado } & \multicolumn{4}{|c|}{ Apropriações } & \multirow{2}{*}{ Total } \\
\hline & Função & Processo & Produto & Tecnologia & \\
\hline Inteligência de Negócios & & 1 & & & 1 \\
\hline Inteligência Competitiva & 5 & 19 & 5 & 6 & 35 \\
\hline Inteligência Empresarial & 1 & 1 & & 1 & 3 \\
\hline Monitoração do Ambiente & 1 & & & & 1 \\
\hline Total & 7 & 21 & 5 & 7 & 40 \\
\hline
\end{tabular}

Fonte: Dados da pesquisa (2014).

A categoria processo foi a que apresentou maior incidência no total de conceitos recuperados. Observa-se que 19 destas apropriações aconteceram pela coincidência do conceito de Inteligência Competitiva.

As categorias função e tecnologia se posicionam em segundo lugar na classificação atestando sete ocorrências cada. Com relação à categoria tecnologia, nela se inserem os três conceitos do corpus que coincidem com o do referencial Inteligência de Negócios (ver tabela 6), o qual justamente se enquadra no sentido de tecnologia para esta pesquisa. Ainda com respeito ao termo Inteligência de Negócios, é muito comum encontrar este termo e seus sinônimos, inclusive no inglês Business Intelligence, em contextos ligados a tecnologia, tendo em vista o amplo portfólio de softwares oferecidos pelo mercado.

Uma análise mais aprofundada desta classificação poderia apresentar conceitos relacionados à Gestão, Sistema Informacional, Disseminação Seletiva da Informação ou Vigilância Tecnológica.

\subsection{Associação de autores por conceito de referência e por categoria}

Nesta seção, ilustra-se, na Tabela 8 , os autores e os respectivos anos em que foi verificada a terminologia coincidente aos termos de 
Inteligência Competitiva e Inteligência de Negócios referenciais. Ressaltase que na cronologia, o ano apresentado significa o ano de publicação do artigo em que conceito foi encontrado ou o ano da obra citada pelo autor para registrar o conceito. Não significa em nenhum dos dois casos exatamente o ano de elaboração daquele conceito. Nesta tabela ainda se encontra os autores que não apresentaram conceitos que coincidissem com os conceitos norteadores deste estudo.

Tabela 8 - Termos de referência por Autores

\section{Conceito de Referência por Autores}

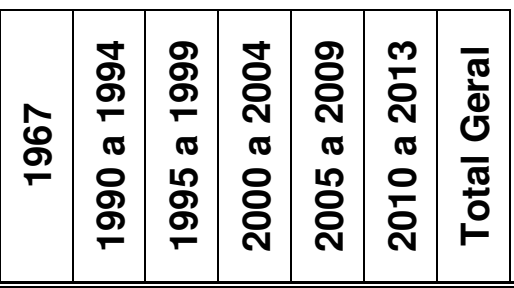

\section{Inteligência Competitiva}

\begin{tabular}{|c|c|c|c|c|c|c|}
\hline JAKOBIAK, F. & 1 & & & & & 1 \\
\hline FULD, L. M. & 1 & 2 & & & & 3 \\
\hline TYSON, K. W. M. & & 2 & & & & 2 \\
\hline HERRING, J. P. & & 1 & & & & 1 \\
\hline KAHANER, Larry. & & 2 & & & & 2 \\
\hline MIQUELINO, F. L. C.; SANTOS, R. N. M. & & & 1 & & & 1 \\
\hline ABRAIC & & & 1 & & & 1 \\
\hline BORGES, M. E. N. & & & 1 & & & 1 \\
\hline COELHO, G. M. et al & & & 1 & & & 1 \\
\hline PRESCOTT, J. E.; MILLER, S. H. & & & 1 & & & 1 \\
\hline TARAPANOFF, $\mathrm{K}$. & & & 2 & & & 2 \\
\hline VALENTIM, M. L. P. et al. & & & 1 & & & 1 \\
\hline QUEYRAS, J.; QUONIAM, L. & & & & 1 & & 1 \\
\hline HOFFMANN, W. A. M. & & & & & 1 & 1 \\
\hline
\end{tabular}

\section{Inteligência de Negócios}

\begin{tabular}{|l|l|l|l|l|l|l|l|}
\hline CUBILLO, Julio & & & 1 & & & & 1 \\
\hline COMBSINC. R. C. A. & & & & 1 & & & 1 \\
\hline
\end{tabular}

\section{Nenhum}

\begin{tabular}{|l|l|l|l|l|l|l|l|}
\hline AGUILAR, F. J. & 1 & & & & & & 1 \\
\hline LAGERSTAM, C. & & 1 & & & & & 1 \\
\hline POZZEBON, M.; FREITAS, H. M. R.; PETRINI, M. & & & 1 & & & & 1 \\
\hline CALOF, J. L. & & & 1 & & & & 1 \\
\hline SCIP & & & 1 & 2 & & 1 & 4 \\
\hline GILAD, B. & & & & 1 & & & 1 \\
\hline TEIXEIRA FILHO, J. & & & 1 & & & 1 \\
\hline TARAPANOFF, K. & & & 1 & & & 1 \\
\hline MILLER, J. P. & & & 1 & & & 1 \\
\hline VALENTIM, M. L. P. et al. & & & 1 & & & 1 \\
\hline MARCIAL, E. & & & & 1 & & 1 \\
\hline
\end{tabular}




\begin{tabular}{|c|c|c|c|c|c|c|c|}
\hline CALOF, J. L.; WRIGHT, S. & & & & & 1 & & 1 \\
\hline SANTOS, R. R. & & & & & 1 & & 1 \\
\hline SOUSA, B. A.; SANTOS, E. T. G. & & & & & & 1 & 1 \\
\hline PERUCCHI, V.; ARAÚJO JÚNIOR, R. H. & & & & & & 1 & 1 \\
\hline TEXEIRA, R. C.; SOUZA, R. R. & & & & & & 1 & 1 \\
\hline Total Geral & 1 & 3 & 11 & 16 & 4 & 5 & 40 \\
\hline
\end{tabular}

Fonte: Dados da pesquisa (2014).

A análise cronológica mostra que os significados estão dispersos na temporalidade, não sendo possível observar agrupamentos de conceitos por períodos em que houvesse a predominância de um ou outro conceito referencial.

$\mathrm{Na}$ Tabela 9, são registrados os autores, classificados pelos conceitos citados nas categorias função, processo, produto e tecnologia, de forma cronológica do ano de publicação do artigo.

Tabela 9 - Classificação dos autores que conceitos atribuídos pelos autores e os anos correspondentes

Apropriações por Autores

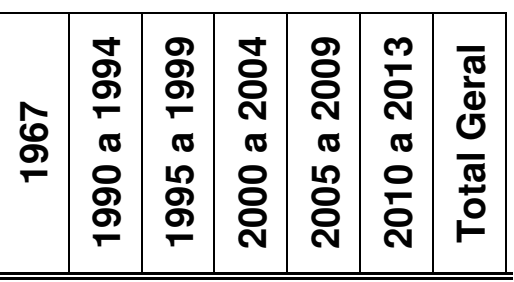

\section{Função}

\begin{tabular}{|c|c|c|c|c|c|c|c|}
\hline AGUILAR, F. J. & 1 & & & & & & 1 \\
\hline LAGERSTAM, C. & & 1 & & & & & 1 \\
\hline SCIP & & & 1 & & & & 1 \\
\hline GILAD, Benjamin & & & & 1 & & & 1 \\
\hline MARCIAL, E. & & & & & 1 & & 1 \\
\hline $\begin{array}{l}\text { SOUSA, Beatriz A. } \\
\text { SANTOS, Edilene T. G. }\end{array}$ & & & & & & 1 & 1 \\
\hline $\begin{array}{l}\text { PERUCCHI, Valmira; } \\
\text { ARAUJO JÚNIOR, Rogério H. }\end{array}$ & & & & & & 1 & 1 \\
\hline
\end{tabular}

\section{Processo}

\begin{tabular}{|c|c|c|c|c|c|c|}
\hline JAKOBIAK, F. & 1 & & & & & 1 \\
\hline FULD, L. M. & & 2 & & & & 2 \\
\hline TYSON, Kirk. W. M. & & 2 & & & & 2 \\
\hline KAHANER, Larry. & & 2 & & & & 2 \\
\hline TARAPANOFF, $\mathrm{K}$. & & & 2 & & & 2 \\
\hline ABRAIC & & & 1 & & & 1 \\
\hline BORGES, Mônica Erichsen Nassif. & & & 1 & & & 1 \\
\hline COELHO, G. M. et al & & & 1 & & & 1 \\
\hline SCIP & & & 2 & & 1 & 3 \\
\hline MILLER, J.P. & & & 1 & & & 1 \\
\hline VALENTIM, M. L. P. et al. & & & 2 & & & 2 \\
\hline QUEYRAS, Joachim; QUONIAM, Luc. & & & & 1 & & 1 \\
\hline HOFFMANN, Wanda Aparecida Machado & & & & & 1 & 1 \\
\hline
\end{tabular}


TEXEIRA, Renata Cristina

SOUZA, Renato Rocha

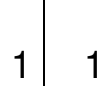

\section{Produto}

\begin{tabular}{|c|c|c|c|c|c|}
\hline FULD, L. M. & 1 & & & & 1 \\
\hline HERRING, J. P. & & 1 & & & 1 \\
\hline POZZEBON, Marlei; FREITAS, Henrique M. R.; PETRINI, Maira. & & 1 & & & 1 \\
\hline PRESCOTT, J. E.; MILLER, S. H. & & & 1 & & 1 \\
\hline SANTOS, Ricardo R. & & & & 1 & 1 \\
\hline
\end{tabular}

\section{Tecnologia}

\begin{tabular}{|c|c|c|c|c|}
\hline CUBILLO, Julio & 1 & & & 1 \\
\hline CALOF, Jonathan L. & 1 & & & 1 \\
\hline TEIXEIRA FILHO, Jayme & & 1 & & 1 \\
\hline TARAPANOFF, $\mathrm{K}$. & & 1 & & 1 \\
\hline COMBSINC. Richard Combs Associates. & & 1 & & 1 \\
\hline MIQUELINO, Fernando L. C.; SANTOS, Raimundo N. M. & & 1 & & 1 \\
\hline CALOF, J. L.; WRIGHT, S. & & & 1 & 1 \\
\hline
\end{tabular}

Fonte: Dados da pesquisa (2014).

É possível observar que uma única categoria, tecnologia, teve uma concentração em determinado período, de 1999 a 2001.

Os autores que coincidem com a apropriação de 'tecnologia', a mesma que o conceito referencial de Inteligência de Negócios:

a)CUBILLO, J.

b)CALOF, J. L.

c)TEIXEIRA FILHO, $\mathrm{J}$.

d)TARAPANOFF, $K$.

e)COMBSINC. R. C. A.

f)MIQUELINO, F. L. C.; SANTOS, R. N. M.

g)CALOF, J. L.; WRIGHT, S.

\section{Considerações finais}

Do estudo relatado, é possível tecer algumas considerações. A primeira delas refere-se à nítida existência de situações de sinonímia e polissemia. Ainda que o termo Inteligência Competitiva tenha sido predominantemente adotado pelos autores, ele se apresenta com uma ampla variedade de conceitos, o que prejudica muito a compreensão do significado que se quer estabelecer no campo. Cabe ressaltar que os termos e conceitos encontrados são oriundos de áreas distintas e, por esta razão, certamente haverá polissemia e sinonímia na compreensão e no uso destes termos. Contudo, as consequências negativas que esta ambiguidade traz para a comunicação científica e tecnológica entre os especialistas podem ser muito negativas. 
Uma segunda consideração refere-se à predominância da categoria processo, sendo que a maioria delas apresentou coincidência como conceito de conceito de Inteligência Competitiva.

Durante a etapa de determinação do conceito norteador de Inteligência Competitiva adotado nesta pesquisa, enfrentou-se alguns dilemas quanto à exatidão do conceito extraído do referencial teórico. $\mathrm{O}$ desafio passou por entender se o conceito de referência representaria o conhecimento gerado pelo processo de aprendizagem, ou era o próprio processo de aprendizagem ou ainda se a gestão informacional geradora do conhecimento e geradora do processo de aprendizagem era a ênfase mais importante. Neste trabalho, considerou-se tanto o conhecimento quanto o processo de gerar o conhecimento, ambos tendo como elemento principal a informação e seu uso para gerar tomadas de decisão que levem a uma vantagem competitiva.

$\mathrm{Na}$ etapa de associação no ano dos autores por conceito de referência e por categoria (função, processo, produto e tecnologia), observou que os significados estão dispersos no tempo, não sobressaindo predominância de um ou outro conceito referencial e que a categoria tecnologia apresentou-se concentrada no espaço entre 1999 e 2001.

Cabe ainda ressaltar as iniciativas de estabelecer os conceitos para os termos em glossários especializados nas áreas de Gestão da Informação, Inteligência Competitiva e Gestão do Conhecimento. A consideração destes na discussão de questões terminológicas é muito importante e contribui para obtenção de maior precisão no uso dos termos. Destaca-se dois destes glossários, um nacional e outro internacional: o Glossário trilíngue de termos em gestão da informação: subárea inteligência competitiva organizacional, da FUNDEPE Editora (CERVANTES et al., 2010) e o Glossary of terms used in competitive intelligence and knowledge management, editado pela ICI e disponível on line (PRIOR, 2010).

Por fim, como estudo futuro sugere-se que a análise dos termos e conceitos em outras áreas certamente mostraria outros aspectos da diversidade terminológica. Como já mencionado anteriormente, a Inteligência Competitiva e a Inteligência de Negócios têm despertado estudos nas áreas de Administração, Ciência da Computação, Economia, Engenharia da Produção e, ainda, Engenharia do Conhecimento. Um estudo terminológico mais aprofundado poderia abranger 0 comportamento destes termos nestas áreas no Brasil e em outros países.

\section{Referências}

AMARAL, R. M. Análise dos perfis de atuação profissional e de competências relativas à inteligência competitiva. 2010. 187 f. Tese (Doutorado em Engenharia de Produção) - Universidade Federal de São Carlos. Disponível em: <www.bdtd.ufscar.br/htdocs/tedeSimplificado//tde_busca>. Acesso em: 20 out. 2014. 
BERGERON, P.; HILLER, C. A. Competitive intelligence. Annual review of information science and technology, v. 36, n. 1, p. 353-390, 2002.

CABRÉ, M. T. La terminología: teoría, metodología, aplicaciones. Barcelona: Atártida/Empúries, 1993.

CERVANTES, B. M. N. et al. Glossário trilíngue de termos em gestão da informação: subárea inteligência competitiva organizacional. Marília: FUNDEPE; São Paulo: Cultura Acadêmica, 2010.

CHOO, C. W. A organização do conhecimento: como as organizações usam a informação para criar significado, construir conhecimento e tomar decisões. São Paulo: Senac, 2003.

CUNHA, M. B. DA; CAVALCANTI, C. R. DE O. Dicionário de biblioteconomia e arquivologia. Brasília: Briquet de Lemos, 2008.

GUADIN, F. La Socioterminologie. Langages, v. 39, n. 157, p. 80-92, 2005.

Disponível em:

<http://www.persee.fr/web/revues/home/prescript/article/lgge_0458-

726x_2005_num_39_157_976\# >. Acesso em: 17 nov. 2014.

GIBBONS, P. T.; PRESCOTT, J. E. Parallel competitive intelligence processes in organisations. International Journal of Technology Management, v. 11, n. 1, p. 162-178, 1996.

MATHEUS, R. F.; PARREIRAS, F. S. Inteligência empresarial versus Business Intelligence: abordagens complementares para o apoio à tomada de decisão no Brasil. Congresso Anual da Sociedade Brasileira de Gestão do Conhecimento, v. 3, p. 1-15, 2004. Disponível em: <http://www.fernando.parreiras.nom.br/publicacoes/ie_bi.pdf>. Acesso em: 30 set. 2014.

PERUCCHI, V.; ARAÚJO JÚNIOR, R. H. de. Produção científica sobre inteligência competitiva da Faculdade de Ciência da Informação da Universidade de Brasília. Perspectivas em Ciência da Informação, v. 17, n. 2, p. 37-56, 2012.

PINHEIRO, L. V. R. Inteligência competitiva como disciplina da ciência da informação e sua trajetória e evolução no Brasil. São Paulo: Saraiva, 2005.

PRIOR, V. Glossary of terms used in competitive intelligence and knowledge management. Butzbach: ICI, 2010. Disponível em: < http://www.institute-for-competitive-

intelligence.com/download/Intelligence\%20Glossary\%20_US_.pdf>.

Acesso em: 30 set. 2014.

TODESCO, J. L.; CARRETERO, L. E.; DURAN, A. Business Intelligence. [Slides]. In: CURSO DE BUSINESS INTELLIGENCE. Escuela Complutense Latinoamericana, Florianópolis, 2007. 